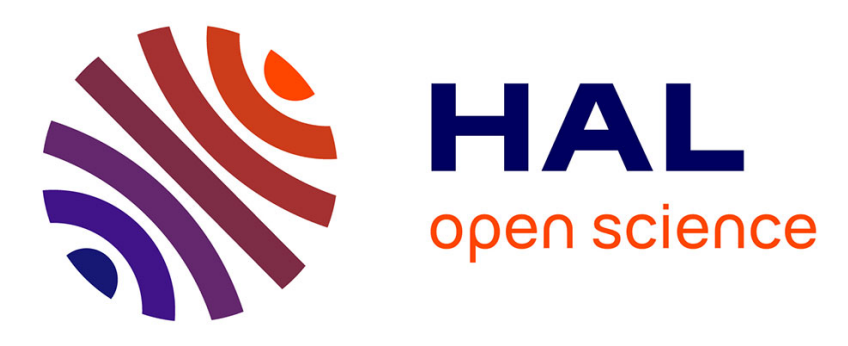

\title{
Determination of the viscous characteristic length in air-filled porous materials by ultrasonic attenuation measurements
}

Philippe Leclaire, Luc Kelders, Walter Lauriks, Christ Glorieux, Jean Thoen

\section{- To cite this version:}

Philippe Leclaire, Luc Kelders, Walter Lauriks, Christ Glorieux, Jean Thoen. Determination of the viscous characteristic length in air-filled porous materials by ultrasonic attenuation measurements. Journal of the Acoustical Society of America, 1996, 10.1121/1.415378 . hal-01330321

\section{HAL Id: hal-01330321 \\ https://hal.science/hal-01330321}

Submitted on 10 Jun 2016

HAL is a multi-disciplinary open access archive for the deposit and dissemination of scientific research documents, whether they are published or not. The documents may come from teaching and research institutions in France or abroad, or from public or private research centers.
L'archive ouverte pluridisciplinaire HAL, est destinée au dépôt et à la diffusion de documents scientifiques de niveau recherche, publiés ou non, émanant des établissements d'enseignement et de recherche français ou étrangers, des laboratoires publics ou privés.

\section{(c)(1)}

Distributed under a Creative Commons Attribution| 4.0 International License 


\title{
Determination of the viscous characteristic length in air-filled porous materials by ultrasonic attenuation measurements
}

\author{
P. Leclaire, L. Kelders, W. Lauriks, C. Glorieux, and J. Thoen \\ Laboratorium voor Akoestiek en Thermische Fysica, Departement Natuurkunde, Katholieke Universiteit \\ Leuven, Celestijnenlaan 200D, 3001 Leuven, Belgium
}

\begin{abstract}
The concept of viscous characteristic length is used to describe the acoustical behavior of fluid-saturated porous media in the high-frequency regime. A method to determine this parameter consists of measuring the wave attenuation in the high-frequency limit. This method has already been used for porous materials saturated by superfluid ${ }^{2} \mathrm{He}$. It is tested in the case of air-filled absorbent materials in a frequency range of $[50-600 \mathrm{kHz}]$. The thermal characteristic length is assumed to be known or measured independently. Two examples are presented. In the first one the method is usable and the viscous characteristic length $\Lambda$ is deduced from the high-frequency behavior of the attenuation per cycle. In the second example, an additional attenuation occurs at high frequencies and only an estimate of $\Lambda$ can be given. Nevertheless, the estimation appears to be rather accurate. The values obtained by this method are compared to those determined by a nonlinear fit of the dispersion curves.
\end{abstract}

\section{INTRODUCTION}

Allard ${ }^{1}$ has shown that absorbent materials can be well described with the help of Biot's theory and has given an excellent review of theoretical and experimental research on the acoustics of air-saturated porous media. Biot's theory ${ }^{2,3}$ shows that the propagation of elastic waves in a fluidsaturated porous solid depends on several macroscopic parameters, i.e., the porosity, the elastic constants, the densities of the phases, and the tortuosity of the material. The wave dispersion in the low-frequency range involves two additional measurable parameters: the fluid viscosity $\eta$ and the solid permeability $\kappa$. The characteristic frequency $f_{c}$ separating the low-frequency and high-frequency regimes is given by

$$
f_{c}=\eta \phi / \kappa \rho,
$$

where $\phi$ is the porosity and $\rho$ the fluid density. For frequencies higher than $f_{c}$, the complexity of the pore geometry cannot be accounted for by the "static" permeability alone and dynamic parameters, related to the pore shape, must be introduced. Biot ${ }^{3}$ defined a structural factor and a sinuosity factor, Attenborough ${ }^{4}$ used a static and a dynamic shape factor and Johnson et al. ${ }^{5}$ introduced the convenient concept of a viscous characteristic length $\Lambda$. These different approaches are equivalent ${ }^{5}$ but the physical significance of the parameter $\Lambda$ appears to be clearer. Furthermore, Johnson et al. ${ }^{5}$ have proposed a conceptually simple method for the determination of $\Lambda$ from the measurement of the high-frequency limit of the attenuation per cycle $1 / Q$.

In this paper, we apply the method proposed by Johnson et al. ${ }^{5}$ for the determination of the viscous characteristic length $\Lambda$ of air-filled materials. A description of this method is given in Sec. I. We also use another method consisting in a nonlinear fit (NLF) for all frequencies of the experimental data on the attenuation. This method gives a value of $\Lambda$ and also of the thermal characteristic length $\Lambda^{\prime}$. Although the thermal effects can be neglected in water-saturated porous media, this is not the case for air-filled materials at audible frequencies and both $\Lambda$ and $\Lambda^{\prime}$ are important. The additional length $\Lambda^{\prime}$ was introduced by Champoux and Allard. ${ }^{6}$ The NLF method will be used essentially to obtain a theoretical reference value of $\Lambda^{\prime}$ necessary for determining $\Lambda$ in the first method.

\section{METHOD}

In the high-frequency limit, the attenuation per cycle is given by ${ }^{5}$

$$
\lim _{\omega \rightarrow \infty} \frac{1}{Q}=\frac{\delta}{\Lambda},
$$

where $\delta=\sqrt{2 \eta / \omega \rho}$ is the viscous skin depth at the angular frequency $\omega$. The quality factor $Q$ can be expressed as a function of the phase velocity $V_{\varphi}$ and of the attenuation coefficient $\alpha$ :

$$
Q=\frac{1}{2} \frac{\omega}{\alpha V_{\varphi}} \text {. }
$$

According to Eqs. (2) and (3), $\alpha$ and $Q$ behave as the square root of frequency and the product $Q \delta$ tends to the unknown parameter $\Lambda$. $\Lambda$ can therefore be determined by measuring the attenuation per cycle $1 / Q$ in the highfrequency limit. This method has been applied to measure Biot's structural factor in superfluid ${ }^{2} \mathrm{He}$ saturated porous media. ${ }^{7.8}$ The unusual properties of such a fluid are of great interest for probing porous media but the practical generalization of the method does not seem to be evident.

Nagy et al. ${ }^{9}$ have demonstrated that even if it is highly attenuated, Biot's slow wave can be excited and detected at ultrasonic frequencies in artificial and real rocks saturated with air. Allard et al. ${ }^{10}$ have determined the tortuosity of airfilled materials using the method given by Johnson et al. ${ }^{11}$ 
This method consists in measuring the high-frequency limit velocity of the slow wave. We are interested here in attenuation measurements at ultrasonic frequencies. The use of ultrasonics ${ }^{10}$ in air-filled materials appears to be an attractive alternative and complementary technique to the methods used for characterizing absorbent materials from measurements at audible frequencies. ${ }^{1,12}$

The characteristic lengths can be related to the permeability, the porosity, and the tortuosity $\alpha_{\infty}$ by b $^{1,5}$

$$
\Lambda==\frac{1}{c}\left(\frac{8 \alpha_{\infty} \kappa}{\phi}\right)^{1 / 2}
$$

and

$$
\Lambda^{\prime}=c^{\prime}\left(\frac{8 \alpha_{\infty} \kappa}{\phi}\right)^{1 / 2}
$$

where $c$ and $c^{\prime}$ are shape factors whose order of magnitude lies between 0.3 and 3 for most materials ${ }^{1,5}\left(c=c^{\prime}=1\right.$ for cylindrical pores with circular cross section). Taking the viscous and thermal effects into account and in the approximation of a rigid frame, the complex wave number at high frequencies for air is given by ${ }^{12}$

$$
k=\frac{\omega}{c_{0}} \sqrt{\alpha_{x}}\left[1+(1-j) \frac{\delta}{2}\left(\frac{1}{\Lambda}+\frac{\gamma-1}{B \Lambda^{\prime}}\right)\right],
$$

where $c_{0}$ is the speed of sound in air, $B$ the square root of the Prandtl number, and $y$ the specific heat ratio of air. At sufficiently high frequencies the viscous skin depth $\delta$ tends to zero and the phase velocity tends to $c_{0} / \sqrt{\alpha_{x}}$, thus providing a method for measuring $\alpha_{\infty}$. Equation (6) shows that the addition of the thermal length does not change the comportment law of the attenuation at high frequencies. The highfrequency limit for the attenuation per cycle including the thermal effect, is given by

$$
\lim _{\omega \rightarrow \infty} \frac{1}{Q}=\delta\left(\frac{1}{\Lambda}+\frac{\gamma-1}{B \Lambda^{\prime}}\right) .
$$

\section{EXPERIMENTAL DETAILS}

Transmission experiments are performed on highporosity polyurethane foams (Recticel Wetteren, Belgium) in the frequency range of 50 to $600 \mathrm{kHz}$. We used broadband air-coupled capacitive transducers of about $1-\mathrm{cm}$ diameter with vibrating Mylar membranes with a thickness of $6 \mu \mathrm{m}$. The emitter is excited by a pulse (with an amplitude of about $350 \mathrm{~V}$ and a duration of $1 \mu \mathrm{s}$ ) provided by a Hameg HM8130 function generator coupled to an ENI 240L power amplifier. The receiver is situated at about $4 \mathrm{~cm}$ from the emitter. The detected signals are amplified with a Cooknell SU2/C amplifier and captured by a Lecroy 9310M oscilloscope. The velocity and attenuation are determined from the

TABLE I. Sample characteristics.

\begin{tabular}{ccccc}
\hline \hline Sample & Porosity & Tortuosity & Permeability $\left(\mathrm{m}^{2}\right)$ & $f_{c}(\mathrm{kHz})$ \\
\hline w1 & 0.98 & 1.06 & $1.42 \times 10^{-9}$ & 13 \\
w2 & 0.97 & 1.12 & $2.06 \times 10^{-9}$ & 9 \\
\hline
\end{tabular}

TABLE Il. Propertie; of air used in the calculations.

\begin{tabular}{cccc}
\hline \hline $\begin{array}{c}\text { Density }\left(20^{\circ} \mathrm{C}\right) \\
\left(\mathrm{kg} / \mathrm{m}^{3}\right)\end{array}$ & $\begin{array}{c}\text { Dynamic viscosity } \\
\left(\mathrm{kg} \mathrm{m}^{-1} \mathrm{~s}^{-1}\right)\end{array}$ & $\begin{array}{c}\text { Specific heat } \\
\text { ratio } C_{p} / C_{v}\end{array}$ & $\begin{array}{c}\text { Prandtl number } \\
B^{2}\end{array}$ \\
\hline 1.2 & $1.85 \times 10^{-5}$ & 1.4 & 0.71 \\
\hline \hline
\end{tabular}

variations of phase and amplitude, respectively, by inserting samples of different thicknesses between the transducers.

\section{RESULTS}

The results for two samples (w1) and (w2) are presented. The sample characteristics are given in Table I. Their thicknesses lie between 2.0 and $9.6 \mathrm{~mm}$ for the first sample wl and between 1.8 and $8.8 \mathrm{~mm}$ for the second sample w2. The tortuosity of the sample was determined using the method of Allard et al. ${ }^{10}$ the porosity and the permeability were measured using the standard techniques. ${ }^{13,14}$ The values of the properties of air used in the analysis are summarized in Table II.

Figures 1 and 2 show the results obtained for several thickness differences $\Delta h$ for the sample wl and for the sample w2. The velocity [Figs. 1(a) and 2(a)] and attenuation
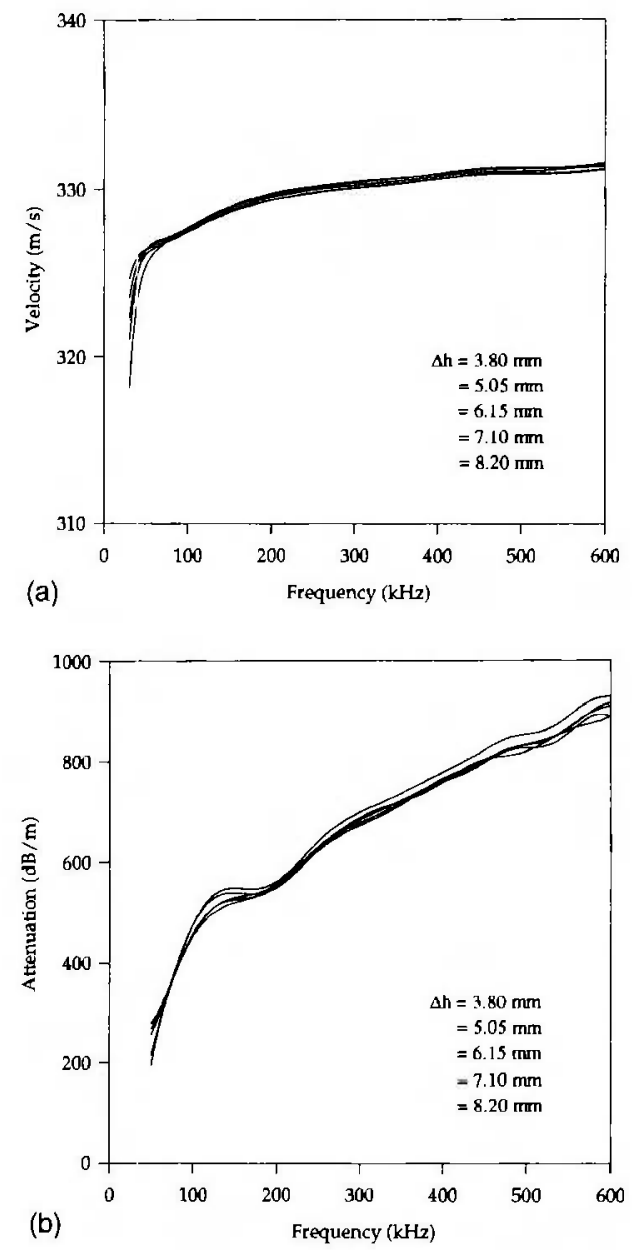

FIG. 1. (a) Phase velocity of the airborne wave as a function of frequency (foam w1). The velosity is determined from the phase difference between the signals obtained in samples of different thicknesses. $\Delta h$ represents the effective thickness crossed by the wave. (b) Attenuation of the airborne wave as a function of frequency for several thickness differences (foam wl). 

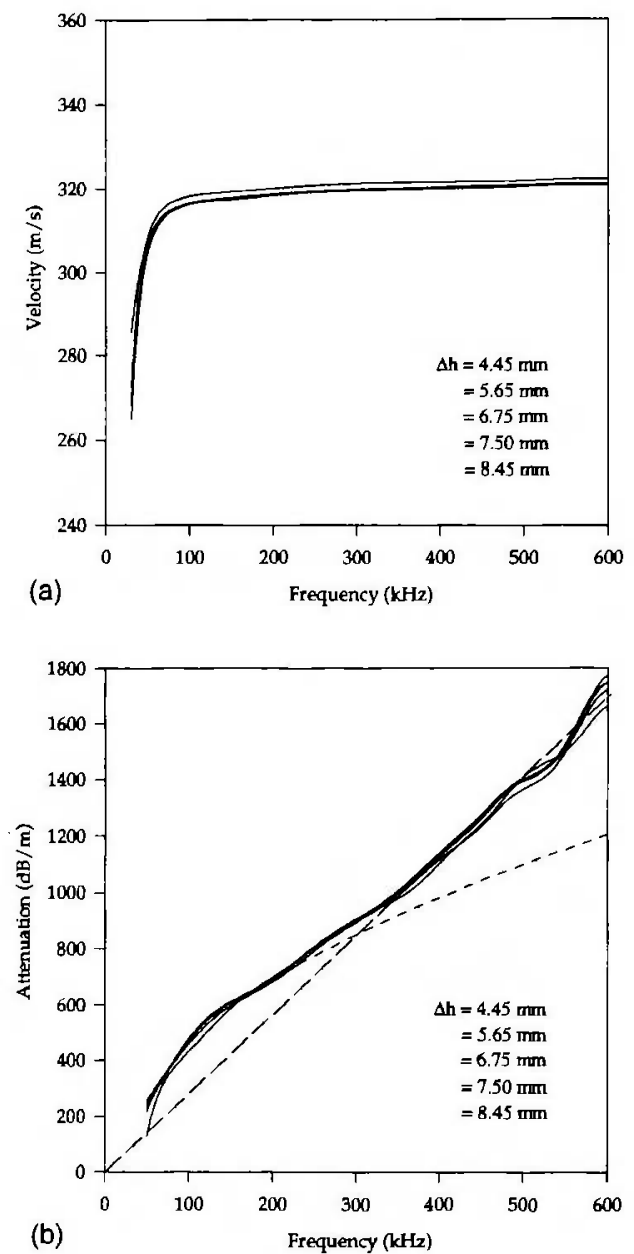

FIG. 2. (a) Phase velocity of the airborne wave as a function of frequency for several thickness differences (foam w2). (b) Attenuation of the airborne wave as a function of frequency for several thickness differences (foam w2). The short dashed curve was obtained from a nonlinear fit of the experimental data between 60 and $220 \mathrm{kHz}$. The experimental attenuation curves deviate from the theoretical behavior for frequencies higher than $200 \mathrm{kHz}$ and seam to follow a linear law (long dashed line) for frequencies above 300 $\mathrm{kHz}$

[Figs. 1(b) and 2(b)] were fairly reproducible between 100 and $600 \mathrm{kHz}$ and for thickness differences $\Delta h$ between 4 and $8 \mathrm{~mm}$. For this reason, no impedance correction had to be made. In Fig. 3, we have plotted the averaged attenuation in the two samples as a function of the square root of frequency. The plot is made between $300 \sqrt{\mathrm{Hz}}$ and $800 \sqrt{\mathrm{Hz}}$ where the attenuation is quite reproducible. For high values of $\sqrt{f}$, the attenuation seems to reach a simple linear asymptote for the first sample (wl) as expected ${ }^{3,5}$ but the second sample (w2) does not follow this law. This may be a consequence of an additional high-frequency attenuation mechanism. Such a phenomenon has already been observed by Nagy. ${ }^{15} \mathrm{He}$ has shown that for some air-saturated porous materials, the attenuation does not behave as the square root of frequency at high frequencies but seems to follow a linear law. Nagy ${ }^{15}$ has proposed several possible explanations for this discrepancy between theory and experiment, such as the scattering of the slow wave in permeable solids at high frequencies or the variation of the dynamic permeability due to the pore size distribution. Elsewhere, Gist ${ }^{6}$ has shown that the pore-wall

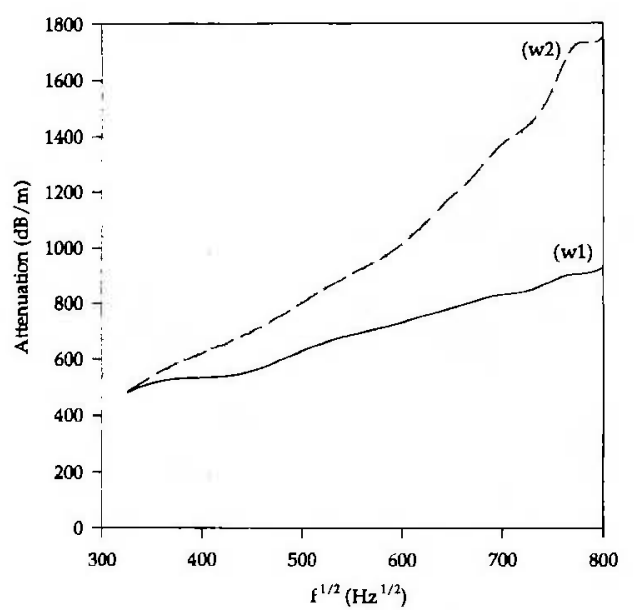

FIG. 3. Average attenuation as a function of the square root of frequency. Sample wl confirms the theoretical predictions (Refs. 2 and 5) and the attenuation reaches a linear asymptote at high frequencies. Sample w2 does not follow the theoretical predictions and the attenuation is not a linear function of $\sqrt{f}$.

roughness can increase the attenuation if the viscous skin depth is smaller than the length scale of the surface roughness. The quantity $Q \delta$ has been plotted as a function of frequency in Fig. 4 after averaging the velocity and attenuation curves of Fig. 1 and 2. For the first sample (w1), this quantity tends to an asymptotic value of about $155 \mu \mathrm{m}$ at high frequencies. For the second sample (w2), $Q \delta$ decreases constantly as the frequency increases. Figure 2 (b) shows that attenuation starts to deviate from the square root law at a frequency of about $200 \mathrm{kHz}$. The value of $Q \delta$ at this frequency is about $122 \mu \mathrm{m}$. From Eq. (7) follows that the highfrequency limit of $Q \delta$ corresponds to the length $\left[\Lambda^{-1}+(y-1)\left(B \Lambda^{\prime}\right)^{-1}\right]^{-1}$. In the first example, the experiment leads to a direct measurement of this quantity while only an estimate is given in the second one.

Henry et al. ${ }^{17}$ proposed recently a method for the determination of the thermal length from the measurement of the specific area using a BET. ${ }^{18}$ The specific areas for the sample

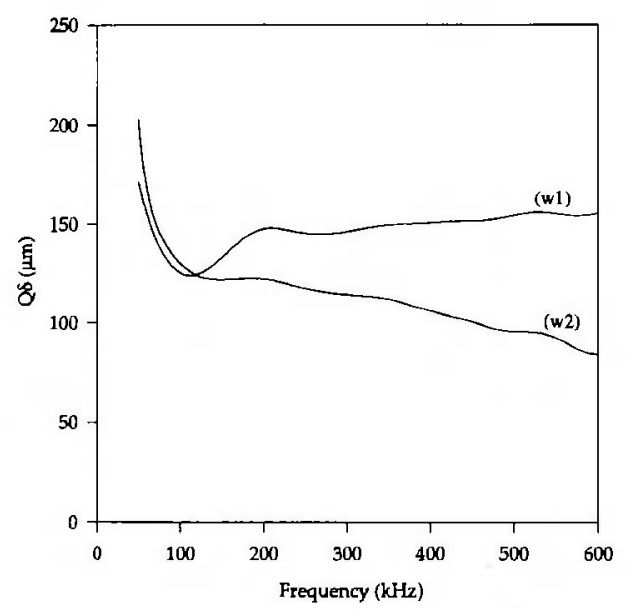

FIG. 4. Product of the viscous skin depth $\delta$ and the quality factor $Q$ as a function of frequency after averaging the velocity and attenuation curves for the two samples. 
TABLE III. Results for the characteristic lengths $\Lambda$ and $\Lambda^{\prime}$ and the shape factor $c$ and $c^{\prime}$

\begin{tabular}{cccccc}
\hline \hline Sample & $\begin{array}{c}\Lambda^{\prime}(\mu \mathrm{m}) \\
(\mathrm{NLF})\end{array}$ & $\begin{array}{c}\Lambda(\mu \mathrm{m}) \\
(\mathrm{NLF})\end{array}$ & $\begin{array}{c}c \\
(\mathrm{NLF})\end{array}$ & $\begin{array}{c}c^{\prime} \\
(\mathrm{NLF})\end{array}$ & $\Lambda(\mu \mathrm{m})$ \\
\hline w1 & 291 & 199 & 0.56 & 2.6 & $207 \pm 13$ \\
W2 & 287 & 147 & 0.94 & 2.1 & $153 \pm 9$ \\
\hline \hline
\end{tabular}

studied are of the order of or less than $1 \mathrm{~m}^{2} / \mathrm{g}$. This requires the use of a BET of a nonstandard-type and rare gases. We have preferred the fitting of the experimental data with the help of the FORTRAN procedure MINUIT. ${ }^{19}$ The fitting expression is given by Biot's theory applied to absorbent materials, ${ }^{1}$ including the viscous length of Johnson et al. ${ }^{5}$ and the thermal length of Champoux and Allard. ${ }^{6}$ A good stability is found when all the parameters except $\Lambda$ and $\Lambda^{\prime}$ are fixed in the fitting process, and the results are not much affected by variations of the input parameters. For the second sample, the fit has been limited to a frequency of $220 \mathrm{kHz}$ because of the deviation of the attenuation curve from the theoretical square root law. The useful bandwidth of about $120-220 \mathrm{kHz}$ being rather narrow for this sample, we have performed an additional experiment at lower frequencies using a Brüel \& Kjaer microphone as detector, allowing a fit to a larger useful range $(60-220 \mathrm{kHz})$. The values of $\Lambda^{\prime}$ and $\Lambda$ obtained from the fit are 291 and $199 \mu \mathrm{m}$, for the first sample and 287 and $147 \mu \mathrm{m}$, for the second sample. Our samples are very similar to those studied by Henry et al. ${ }^{17}$ except for the permeabilities. This gives an opportunity to make a comparison when only one parameter differs and allows one to assess its influence. The thermal characteristic length $\Lambda^{\prime}$ is defined as twice the pore volume to surface ratio and is related to the permeability $\kappa$. According to Eq. (5), $\Lambda^{\prime}$ is proportional to the square root of $\kappa$. The permeabilities of our samples $\left(1.42 \times 10^{-9}\right.$ and $\left.2.06 \times 10^{-9} \mathrm{~m}^{2}\right)$ being significantly smaller than those of Henry et al. ${ }^{17}\left(2.64 \times 10^{-9}\right.$ and $\left.3.36 \times 10^{-9} \mathrm{~m}^{2}\right)$, our values of $\Lambda^{\prime}$ are noticeably smaller than theirs. This remark assumes that the shape factor $c^{\prime}$ is fairly constant for all the samples. The value of $c^{\prime}$ is about 2.5 for the two samples of Ref. 17 and the values obtained here are 2.6 and 2.1. According to Eq. (4), $\Lambda$ should be smaller for our samples than for those of Ref. 17, but it seems that $c$ is more variable than $c^{\prime}$ from one sample to another. The values of $c$ in Ref. 17 are 0.89 and 0.63 while they are 0.56 and 0.94 for our samples.

Using the method described in the first paragraph, the viscous characteristic length $\Lambda$ is also derived for the two samples $w 1$ and $w 2$ from the length $Q \delta=\left[\Lambda^{-1}\right.$ $\left.+(\gamma-1)\left(B \Lambda^{\prime}\right)^{-1}\right]^{-1}$ from Fig. 4 , where $\Lambda^{\prime}$ is replaced by the reference value obtained from the fit. The results are reported in Table III. The values obtained for $\Lambda$ are $207 \mu \mathrm{m}$ for the first sample and $153 \mu \mathrm{m}$ for the second sample. These results are close to the values of $\Lambda$ obtained directly from the fit. The relative difference compared to the NLF method is $4 \%$ for the first sample and $3.5 \%$ for the second sample. This very good result for the second sample is surprising as only an estimate is given. This is probably due to the fact that the characteristic frequency $f_{c} \approx 9 \mathrm{kHz}$ is rather low because of the high permeability of the sample. We can therefore con- sider that we are in Biot's high-frequency regime at $200 \mathrm{kHz}$ so that $Q \delta$ has almost reached its high-frequency limit. At high frequencies in Figs. 1 and 2, the error is about $40 \mathrm{~dB} / \mathrm{m}$ for the attenuation and less than $1 \mathrm{~m} / \mathrm{s}$ for the velocity resulting in a relative error on $Q$ [see Eq. (3)] of about $4.5 \%$. According to $\mathrm{Eq}$. (7), the maximum relative error on $\Lambda$ is given by

$$
\left|\frac{\Delta \Lambda}{\Lambda}\right|=\left(1+\frac{\gamma-1}{B} \frac{\Lambda}{\Lambda^{\prime}}\right)\left|\frac{\Delta Q}{Q}\right|,
$$

giving a numerical value of $6 \%$ (i.e., $\Delta \Lambda=13 \mu \mathrm{m}$ ) for the first sample and $5.6 \%$ (i.e., $\Delta \Lambda=9 \mu \mathrm{m}$ ) for the second sample. We hasten to say that $\Lambda^{\prime}$, which is obtained from the nonlinear fit, is considered as a theoretical value in Eq. (7) and is assumed to be known without error. In fact the uncertainty on $\Lambda^{\prime}$ should be added and the error on $\Lambda$ is larger or at best equal to the error on $\Lambda^{\prime}$. Nevertheless, the measurement of the length $\left[\Lambda^{-1}+(\gamma-1)\left(B \Lambda^{\prime}\right)^{-1}\right]^{-1}$ appears to be rather accurate and the method can be considered as reliable, provided it is possible to determine $\Lambda^{\prime}$ with a good precision.

\section{CONCLUSION}

We have determined the viscous characteristic length $\Lambda$ of air-filled absorbent materials from the measurement of the ultrasonic attenuation. This method assumes that the thermal characteristic length $\Lambda^{\prime}$ can be determined independently. Here, $\Lambda^{\prime}$ can be determined using the method proposed by Henry et al. ${ }^{17}$ measuring the specific area with the standard BET technique. ${ }^{8}$ We have preferred a nonlinear fit of the experimental data providing reference values for $\Lambda^{\prime}$ and $\Lambda$. For one of the samples (w2), only an estimation of $\Lambda$ can be given due to the extra attenuation already observed by Nagy. ${ }^{15}$ Nevertheless, the estimation is fairly accurate due to the fact that the high-frequency regime is reached quickly (at $f_{c} \approx 9 \mathrm{kHz}$ ), long before that the discrepancy between the experimental data and the theoretical highfrequency behavior ${ }^{5}$ appears (at $200 \mathrm{kHz}$ ). The velocity and attenuation measurements appear to be fairly reliable and reproducible in a substantial frequency range resulting in an error of only $6 \%$ on the measurement of the length $\left[\Lambda^{-1}+(\gamma-1)\left(B \Lambda^{\prime}\right)^{-1}\right]^{-1}$.

\section{ACKNOWLEDGMENTS}

This work was supported by the SAVANTE Program of the European U.H.C.M. Contract No. CHRX-CT93-0397.

\footnotetext{
' J. F. Allard, Sound Propagation in Porous Media: Modeling Sound Absorbing Materials (Elsevier, New York, 1994).

${ }^{2}$ M. A. Biot, J. Accust. Soc. Am. 28, 168 (1956)

${ }^{7}$ M. A. Biot, J. Accust. Soc. Am. 28, 178 (1956).

${ }^{4}$ K. Attenborough, J. Acoust. Soc. Am. 73, 785 (1983).

${ }^{5}$ D. L. Johnson, J. Koplik, and R. Dashen, J. Fluid Mech. 176, 379 (1987).

${ }^{6}$ Y. Champoux and J. F. Allard, J. Appl. Phys. 70, 1975 (1991).

${ }^{7}$ D. Singer, F. Pasierb, R. Ruel, and H. Kojima, Phys. Rev. B 30, 2909 (1984).
} 
${ }^{8}$ S. R. Baker and I. Rudnik, Proc. IEEE Ultrasonics Symposium, 1039 (1985).

${ }_{9}^{9}$ P. B. Nagy, L. Adler, and B. P. Bonner, Appl. Phys. Lett. 56, 2504 (1990).

${ }^{10} \mathrm{~J}$. F. Allard, B. Castagnède, M. Henry, and W. Lauriks, Rev. Sci. Instrum. 65(3), 754 (1994).

${ }^{11}$ D. L. Johnson, T. J. Plona, C. Scala, F. Pasierb, and H. Kojima, Phys. Rev. Lett. 49, 1840 (1982).

${ }^{12}$ D. Lafarge, J. F. Allard, B. Brouard, C. Verhaegen, and W. Lauriks, J. Acoust. Soc. Am. 93, 2474 (1993).

${ }^{13}$ D. A. Bies and H. Hansen, Appl. Acoust. 13, 357 (1980).
${ }^{14}$ C. Zwikker and C. W. Kosten, Sound Absorbing Materials (Elsevier, New York, 1949).

${ }^{15}$ P. B. Nagy, J. Acoust. Soc. Am. 93, 3224 (1993).

${ }^{16}$ G. A. Gist, J. Acoust. Soc. Am. 96, 1158 (1994).

${ }^{17}$ M. Henry, P. Lemarinier, J. F. Allard, J. L. Bonardet, and A. Gédéon, J. Appl. Phys. 77, 17 (1995).

${ }^{18}$ S. Brunauer, P. H. Emmett, and E. Teller, J. Am. Chem. Soc. 60, 309 (1938).

${ }^{19} \mathrm{~F}$. James and M. Roos, MINUIT Function Minimization and Error Analysis (CERN Computer Centre Library, Geneva, 1986), No. 506. 